\title{
Sliding Mode Control of a Miniature Brushless DC Motor
}

\author{
Chizea F. D., Ovie E., Akachukwu C. M., Muazu M. B.
}

\begin{abstract}
The Brushless DC Motor (BLDCM) has been used as the primary actuating component in different types of dynamic controlled systems. Of particular importance to this paper is the control of Miniature BLDCM or very small size BLDCM in the sub-micro scale of inertia which finds application in many new micro-, nano- and pico-systems. The particular control problems being highlighted here is linked to the dimensions of the dynamic parts of this device which at some extreme approaches almost singular values. This might lead to simulation study problems due to presence of singular states in the ensuing dynamics. Other unknown dynamic contributors such as tribology effects from the gearing play a role which is not explicitly shown in the dynamic model but is controlled robustly by the sliding mode controller. The design and utilization of a robust nonlinear control scheme such as the sliding mode controller (SMC) is also presented as a good candidate for controlling such uncertain systems. Simulation results showed good rise time, no overshoot and settling time of $6.2 \mathrm{~s}$
\end{abstract}

Index Terms - singular states, robust control, SMC, mechatronics, system dynamics, simulation, output tracking

\section{INTRODUCTION}

The Brushless DC Motor (BLDCM) is an often used actuator for many control systems. Both the rotary and linear types have found use in many mechatronics systems demonstrating dynamics that range from the simple to the complex [9], [6]. Examples of such systems include DVD player drives, Hard drives, precision robotics[10], hobbyist rotorcraft, attitude control actuators for very small satellites e.g. Reaction and momentum wheel motors, Micro Control Moment Gyros(MCMG) [3],[4], telescope control mechanisms. With the ever growing need for smaller and compact devices or systems, the miniature BLDCM will continue to prove valuable in many technological and engineering applications.

Fig. 1 shows the simplified circuit abstraction of a DC motor [11]. The distinct division of the system shows the coupled electrical and mechanical subsystems. From Fig.1, the main dynamic contributors will be the Electrical inductor and the rotary mass or inertia component.

Dr. Chizea D. Francis, Department of Planning and Research, NASRDA, Abuja, Nigeria,

Dr. Ovie EseOghene, AUAVL/NASRDA, Abuja, Nigeria, +2348066765589 ,

Engr. Akachukwu M. Chichebe, AUAVL/NASRDA, Abuja, Nigeria, $+2348080900900$

Prof. Mu'azu M. Bashir, Dept. of Computer and Control

Engineering, Ahmadu Bello University, Zaria, Nigeria, +2348096211959 ,

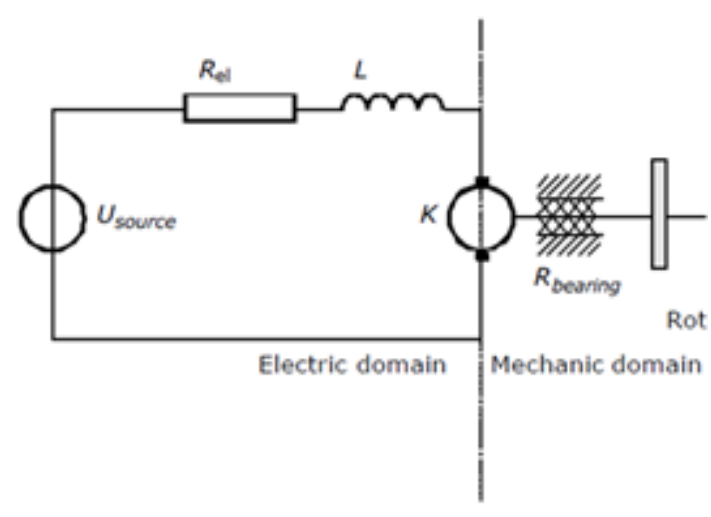

Figure 1: Equivalent BLDCM circuit diagram

The ability to study these systems offline is important, as valuable hardware is preserved or protected from damage which can result from direct online control testing. Also the tuning requirements for these controllers makes online testing a less attractive option for controller experimental studies since imprecise test parameters e.g. gains, could result in damages by burn-out of BLDCM hardware and damage to other control circuitry. The control of such systems using standard classical linear control techniques like the Proportional-Integral-Derivative (PID) controller, proves inadequate to handle the complex (inherently nonlinear) and fast dynamics resulting from small component values and by extension extremely fast and analogous electrical and mechanical time constants. These dimensional parameter variances are studied in this work for a coupled controller and BLDCM system using a robust SMC [12]

However, simulation studies considering the amelioration of the control effort in such miniature actuators, must address the constraints driven by the physics of the device [12]. This amelioration of control effort must be handled with a robust controller [8], [2]. The robust controller being proposed utilizes a sliding mode algorithm (SMA) to compensate for unmodelled dynamic effects and external load-torque variations which could contribute parasitic dynamic behavior to the output of the BLDCM. The proposed scheme has the merit of permitting detailed offline simulation studies on the system before any real-time experiments with the actual device. This will naturally reduce cost of system design and development [15].

The rest of the paper is organized as follows: Section 2 presents the BLDCM dynamic model, Section 3 addresses the development of a suitable Sliding model controller (SMC) for the BLDCM, and Section 4 details the simulation, analysis and discussion of results while it concludes in Section 5. 


\section{BLDCM EQUATIONS}

The model for the BLDCM analysis is abstracted from Fig. 1. The derived model is linear in the coefficients and also time invariant, making it directly both suitable for simulation and control.

$$
\begin{aligned}
& \frac{d i}{d t}=-\frac{R}{L} i-\frac{r}{L} \omega+\frac{E}{L} \\
& \frac{d \omega}{d t}=\frac{r}{J m} i-\frac{R m}{J m} \omega+\frac{T l}{J m} \\
& \frac{d \theta}{d t}=\omega
\end{aligned}
$$

The already simplified dynamic of this system is as given in (1a)-(1c) and reflects the control direction being proposed for this work, which is continuous and precise angular position and angular velocity control.

Where the state vector of the system $\mathrm{x}=[\mathrm{x} 1 ; \mathrm{x} 2 ; \mathrm{x} 3]$ is obtained from $[i, \omega, \theta]$. Equation (2), represents the state space formulation with $i$, $\omega$ selected as the BLDCM system state.

$$
\left(\begin{array}{l}
\dot{x} 1 \\
\dot{x} 2
\end{array}\right)=\left(\begin{array}{cc}
-\frac{R}{L} & -\frac{r}{L} \\
\frac{r}{J m} & -\frac{R m}{J m}
\end{array}\right)\left(\begin{array}{l}
x 1 \\
x 2
\end{array}\right)+\left(\begin{array}{l}
\frac{1}{L} \\
0
\end{array}\right) u
$$

Since $\theta$ is easily derived from the integral of the angular velocity $\omega$, an extended form of (2), is given by (3), which considers the angular displacement dynamic also

$$
\left(\begin{array}{c}
\dot{x} 1 \\
\dot{x} 2 \\
\dot{x} 3
\end{array}\right)=\left(\begin{array}{ccc}
-\frac{R}{L} & -\frac{r}{L} & 0 \\
\frac{r}{J m} & -\frac{R m}{J m} & 0 \\
0 & 1 & 0
\end{array}\right)\left(\begin{array}{l}
x 1 \\
x 2 \\
x 3
\end{array}\right)+\left(\begin{array}{c}
\frac{1}{L} \\
0 \\
0
\end{array}\right) u
$$

\section{SLIDING MODE CONTROLLER FOR BLDCM}

Sliding mode control is selected as the controller of choice for the BLDCM because of uncertain model characteristics. The small scale of the BLDCM creates a unique set of unknown and generally nonlinear characteristics that do not necessarily show in the system model of (1a-1c). Drawing from the characteristics of sliding mode control which include infinite time convergence, robustness to model uncertainties and ease of implementation, we proceed to design the angular velocity and position sliding mode controllers.

\section{A. Overview of Sliding Mode Controller Design}

The sliding mode controller is designed in two parts vis-a-viz the choice of sliding surface and the synthesis of a control law which comprises an equivalent control,( Ueq) and a nominal control part, (Un) [1],[6],[?].

$$
U s m=U e q+U n
$$

, where the nominal control Un is given by

$$
U_{n}=\operatorname{sgn}\left(S_{e}(w)\right)
$$

, with sgn (.), the signum function generally defined as;

$\operatorname{sgn}()=.\left\{\begin{array}{c}1 \text { if } \operatorname{sign}(.)>0, \\ 0 \text { if } \operatorname{sign}(.)=0, \\ -1 \text { if } \operatorname{sign}(.)<0\end{array}\right.$

, for chattering suppression a saturation function is chosen for Un. Other chattering suppression functions exist such as the hyperbolic function and sigmoid function [14].

$U n=\operatorname{Ksat}\left(\frac{\operatorname{Se}(.)}{\phi}\right)$

, where $\mathrm{K}$ is a sufficiently large positive constant [13].

The sliding surface is given by a linear function of the computed error and the error derivatives,

$S()=.\left(\frac{d}{d t}+p\right)^{n-1} e(t)$

, where $n-1$ is the number of error derivatives to be added. Otherwise stated, n-1 describes the relative degree of the system output while e is the computed instantaneous error.

\section{B. Angular Velocity SMC Design for BLDCM}

Utilizing the second order state space model of (2), the error on the angular velocity variable $\omega$ is $e_{\omega}=\omega_{r}-\omega . \omega_{\mathrm{r}}$ and $\omega$ represents the reference and actual angular velocities respectively. This yields the second order sliding surface given by (9) respectively.

$\operatorname{Se}(\omega)=\frac{d}{d t}\left(\omega_{r}-\omega\right)+p\left(\omega_{r}-\omega\right) \equiv\left(\frac{d}{d t}+p\right) e_{\omega}$

Otherwise written as

$\operatorname{Se}(\omega)=\dot{e}_{\omega}+p e_{\omega}$

, with necessary conditions for sliding surface existence being $\operatorname{Se}(0)=0, \operatorname{Se}(0)=0$

$\dot{S} e(\omega)=\ddot{e}_{\omega}+p \dot{e}_{\omega}$

, further parameter simplification utilizes the composed parameters defined as $a=R / L ; b=r / L ; c=r / J m ; d=R m / J m$; e $=\mathrm{Tl} / \mathrm{Jm}$, the equivalent control on the angular velocity is obtained as 
$U^{*}=\frac{L}{c}(\ddot{\omega} \mathrm{r}+\mathrm{p} \omega \mathrm{r}+(\mathrm{ca}+\mathrm{dc}-\mathrm{pc}) \mathrm{i}+\ldots$

$\left.\left(\mathrm{cb}+\mathrm{pd}-\mathrm{d}^{2}\right) \omega\right)$

With $\mathrm{U}^{*}=\mathrm{Ueq}$, the complete SMC defined on the velocity surface requires the nominal term Un

$U_{n}=\operatorname{Ksat}\left(\frac{S_{\omega}(\omega)}{\phi_{\omega}}\right)$

, the complete SMC for the angular velocity becomes the composite control in (4).

\section{Position SMC Design for BLDCM}

The position sliding mode controller is designed similarly on a state space of third order comprising the state vector $\mathrm{x}=$ $[i, \omega, \theta]$. The sliding surface is defined on

$\operatorname{Se}(\theta)=\left(\frac{d}{d t}+p\right)^{2} e$

With the derivative of $\mathrm{xxx}$ being

$\dot{S} e(\theta)=\dddot{e}+2 p \ddot{e}+p^{2} \dot{e}$

Where the error $e_{\theta}=\theta_{r}-\theta$. Further algebra on the sliding surface yields the equivalent control on the angular position as

$U^{*}=\frac{L}{c}(\dddot{\theta} r+2 p \ddot{\theta} r+p 2 \dot{\theta} r+\ldots$

$(c a-d c-2 p c) i+\ldots$

$(c b+2 p d+d 2-p 2) \omega-\ldots$

$(d e+2 p e))$

, with $\mathrm{U}^{*}=\mathrm{Ueq}$, the nominal control is added to complete the SMC formulation as

$U_{n}=\operatorname{Ksat}\left(\frac{S_{e}(\theta)}{\phi_{\theta}}\right)$

\section{SIMULATION \& ANALYSIS}

Motor parameters are obtained from the data sheet [9]. System parameters for the BLDCM are defined as: $\mathrm{p}=1 ; \mathrm{r}=$ $0.749 ; \mathrm{R}=1.47 ; \mathrm{L}=9 \mathrm{e}^{-4} ; \mathrm{Rm}=0.0029 ; \mathrm{Jm}=3.18 \mathrm{e}^{-4} ; \mathrm{Tl}=10$. The choice of the positive parameter $\mathrm{p}$ is almost arbitrary, $\mathrm{r}$ is the motor torque constant, $\mathrm{R}$ the resistance, $\mathrm{L}$ is inductance, $\mathrm{Rm}$ the damping constant, Jm the rotor inertia \& $\mathrm{Tl}$, the load torque. The SMC parameters have ranges $5000<\mathrm{K}<15000$ for the positive constant $\mathrm{K}$ and the boundary layer width parameter varies between $50<\phi<500$. Simulation experiments for angular velocity and position were performed. Some of the results are shown in the Figures below.
Fig. 2-3 show simulation result for the angular velocity tracking. It shows the reference angular velocity, the output angular velocity and the error between the reference and output

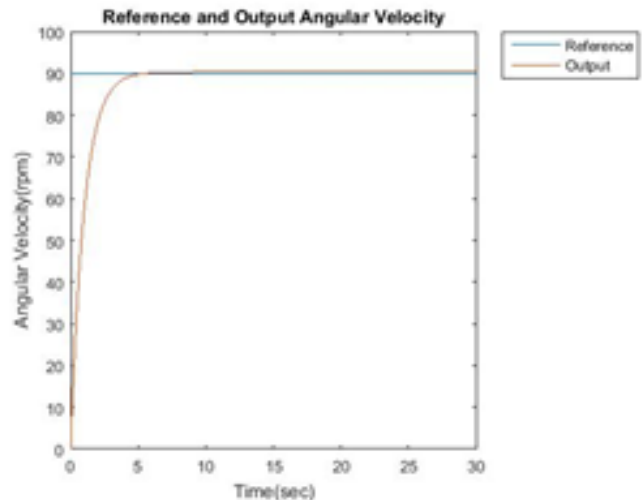

Figure 2: BLDCM Sliding Mode Angular Velocity Output Tracking

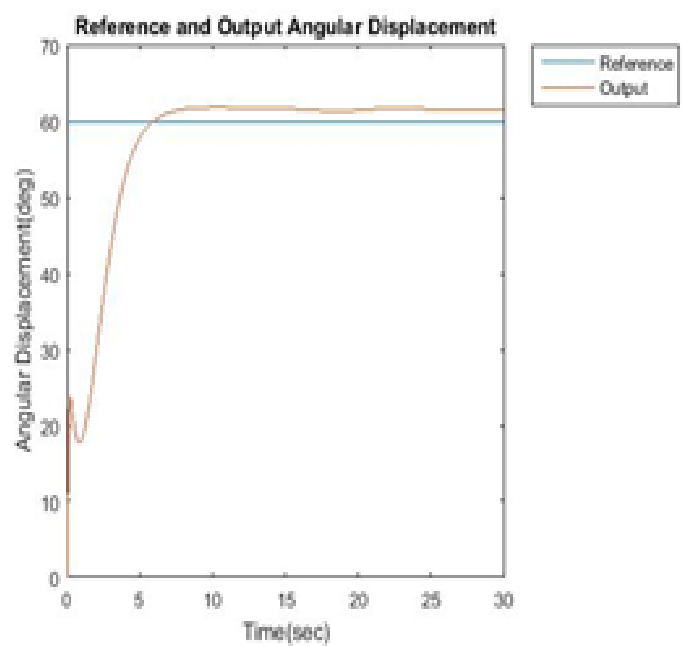

Figure 3: Angular Velocity Output Tracking \& Tracking error

Tracking results for angular displacement are shown in Fig. 4-5. Any desired reference angular displacement is selected between 0 and $2 \pi$ rad (i.e. between $0 \& 360$ degrees).

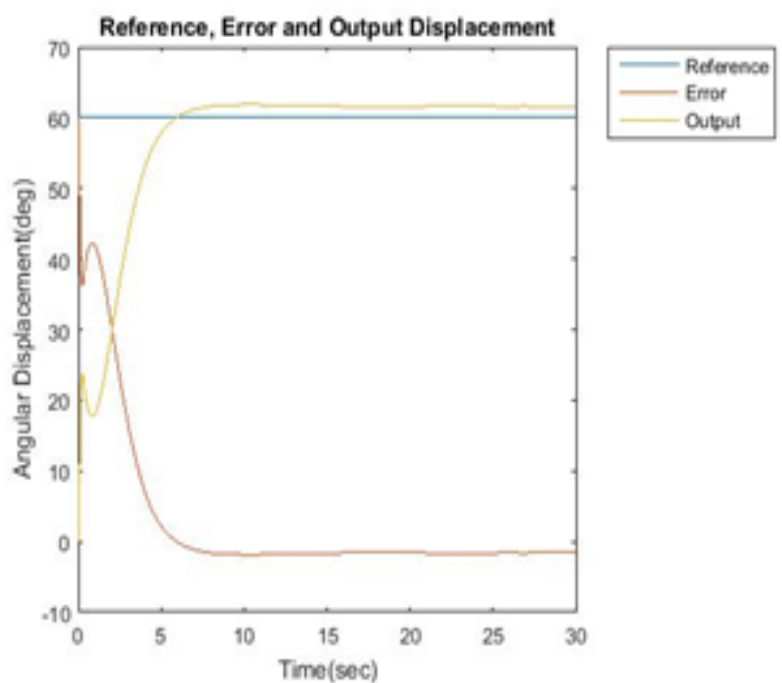

Figure 4: SMC Angular Displacement Output 


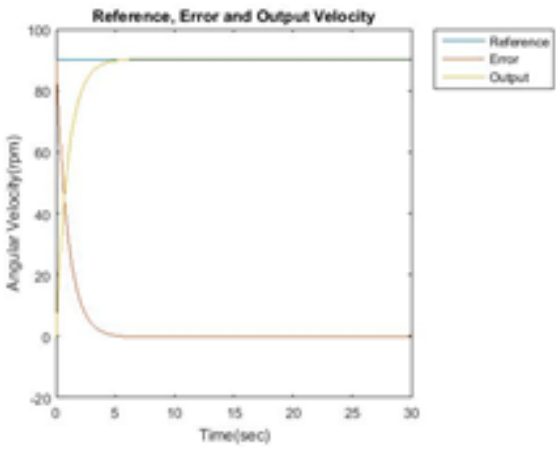

Figure 5: SMC Angular Displacement Output and Tracking error

\section{A. Discussion \& Comments on Simulation Results}

The simulation results show a good tracking of the reference signals for both angular velocity and angular position control. Very importantly, the steady state error almost asymptotically tends towards zero in both cases i.e. with an exponential rate of convergence. We also have seen the system react with quick response time. The response of the BLDCM system is very parameter sensitive and dependent on the physical dimensions of the subcomponents as was seen in the response curves when load torque was inserted. As the motor rotor inertia exceeded the $10^{-6}$ range, singular dynamic effects became prevalent with the simulation encountering singular states during execution. The primary parameters which contribute to this sensitivity include the rotor inertia and motor inductance which coincidentally form the primary energy storage elements and dynamic contributors to the system model.

\section{CONCLUSION}

Two sliding mode controllers have been designed for a miniature BLDCM and experimented with in simulation. The experiments show a good tracking of the reference signals for both the second order angular velocity SMC and the third order angular displacement SMC. However it was observed that the higher order SMC was more sensitive to parameter changes. We suggest the addition of an adaptive control scheme such as fuzzy SMC (FSMC [10]) or FSMC with genetic algorithm (FSMCGA) in further work so as to mitigate against this sensitivity.

\section{REFERENCES}

[1] Utkin, V. (2008). Sliding Mode Control: Mathematical Tools, Design and Applications. Nonlinear and Optimal Control Theory. USA, Spinger Berlin/Heidelberg. 1932/2008: 289-347.

[2] Young, K. D., Utkin, V.I. \& Ozguner, U.(1999).A Control Engineer's Guide to Sliding Mode Control. IEEE TRANSACTIONS ON CONTROL SYSTEMS TECHNOLOGY, VOL. 7, NO. 3

[3] Busseuil, J., Libre, M., \& Rozer, X. (1998). High Precision Mini CMGs and their Spacecraft Applications. Aerospatiale France, AS 98-006.

[4] Ovie, E. (2012). Development of Control laws for a Picosatellite. Master's Thesis, Automatic Control Specialization, Departement Genie Mecanique Conception, INSA de Lyon.

[5] Passino, K.M., \& Quijano, N. (2004). Modeling and System Identification for a DC Servo. Dept. Electrical Engineering, Ohio State University.

[6] Slotine, J.J.E. \& Li, W. (1991). Applied nonlinear control. Prentice-Hall Inc.
[7] Hamerlain, M. (1995). Robust control with reduced knowledge of unmodeled dynamics using sliding mode application to robot manipulators. IEEE conference, pp: 261-268.

[8] Slotine, J.J.E. and Sastry, S.S. (1983). Tracking control of nonlinear systems using sliding surfaces, with application to robot manipulators. Int. J. Control, 38 (2): 465-492.

[9] Faulhaber, F. (2009). Technical data Sheet for BLDCM GmbH \& Co KG Daimler str. 23 / 25. 71101 Schonaich Technical information data.

[10] Piltan, F. \& Sulaiman, N. B. (2012). Review of Sliding Mode Control of Robotic Manipulator. World Applied Sciences Journal 18 (12): 1855-1869. ISSN 1818-4952. IDOSI Publications, 2012 DOI: 10.5829/idosi.wasj.2012.18.12.208

[11] Broenink, J.F. (1999). Introduction to Physical Systems Modelling with Bond Graphs. University of Twente, Dept EE, Control Laboratory PO Box 217, NL-7500 AE Enschede Netherlands

[12] El fahime, B., Rzine, B., Moujibi, N., Saka, A., Bouayad, A. \& Radouani, M. (2010). Modeling, Simulation and Analysis of Mechatronic Systems by Bond Graphs and Monte Carlo Simulations. Journal of Modelling and Simulation of Systems (Vol.1-2010/Iss.4), pp. 204-212.

[13] Unkown. (2007). A Quick Introduction to Sliding Mode Control and Its Applications. Universita Degli Studi Di Cagliari

[14] Sulaiman, M., Patakor, F.A. \& Ibrahim, Z. (2014).New Methodology for Chattering Suppression of Sliding Mode Control for Three-phase Induction Motor Drives. WSEAS TRANSACTIONS on SYSTEMS and CONTROL, E-ISSN: 2224-2856, Volume 9, pp. www.erpublication.org. International Journal of Engineering and Technical Research (IJETR)

[15] Karnoop, Rosenberg \& Margolis. (2011). Modeling, Simulation and Control of Dynamic systems. Elsevier's Press. 